F. Child Lang. 32 (2005), I39-158. (c) 2005 Cambridge University Press DOI: I0.1017/So305000904006622 Printed in the United Kingdom

\title{
Large constituent families help children parse compounds*
}

\author{
ANDREA KROTT \\ School of Psychology, University of Birmingham, UK \\ $\mathrm{AND}$ \\ ELENA NICOLADIS \\ Department of Psychology, University of Alberta, Canada
}

(Received 28 Fuly 2003. Revised 24 fune 2004)

\begin{abstract}
The family size of the constituents of compound words, or the number of compounds sharing the constituents, has been shown to affect adults' access to compound words in the mental lexicon. The present study was designed to see if family size would affect children's segmentation of compounds. Twenty-five English-speaking children between 3;7 and 5;9 were asked to explain the meaning of existing compounds with constituents of varying family size to an alien puppet. The results showed that children were more likely to mention the modifier of compounds if they came from large constituent families than if they came from small constituent families. Other variables were also shown to have some, but smaller effects on children's parsing, including the frequency of the constituent words and the compounds, whether the compounds were already known, and age. These results suggest that children's segmentation of compounds might be facilitated by analogy with other compounds already in their vocabularies.
\end{abstract}

\section{INTRODUCTION}

When children initially use compound words such as apple juice, they probably do not know that they are using a word that can be decomposed into two constituents (Berko, I958; Clark \& Berman, I984). As children get

[*] This research was supported by a NSERC Research Grant to the second author. An earlier version has been presented at the 25th Annual Meeting of the German Linguistics Society (Deutsche Gesellschaft für Sprachwissenschaft) in Munich, February 26-28, 2003. We thank Trinity Wilson for collecting and coding the data for this study and Christina Gagné for helpful feedback. Address for correspondence: Andrea Krott, School of Psychology, University of Birmingham, Edgbaston, Birmingham B 5 2 TT, UK. tel: +33 (o)I2I 4I4 4903; fax: +33 (o)I2I 4I44897; e-mail: a.krott@bham.ac.uk 
older, however, they learn the basic principle of noun-noun compounding. In languages in which compounding is highly productive, like English, Swedish, and Dutch, children start to coin novel noun-noun compounds such as nose-beards to refer to moustaches (Clark, I993; Becker, I994). Novel noun-noun compounds occur in English-speaking children's spontaneous speech before two years of age (Clark, I98I, I983; see also Mellenius, I 997). In experiments eliciting novel compounds, English children perform well by the age of $3 ; 0$, Swedish children by the age of 4 ; 0 (Clark, Gelman \& Lane, I985; Mellenius, I997). Children acquiring languages in which compounding is not very productive, like Hebrew or French, have been shown to form novel noun-noun compounds later in development (Clark \& Berman, i987; Clark, I998). Spontaneous Hebrew compounding starts around $5 ; \circ$, and children perform well in an elicitation experiment from the age of 6; (Clark \& Berman, I987). In comprehension experiments, children acquiring compounding languages are well able to parse novel compounds from the age of 3; (Clark et al., I985; Mellenius, I 997; Nicoladis, 2003), while children acquiring Hebrew perform well from the age of 4; (Berman \& Clark, I 989).

Research on children's ability to form and understand novel compounds suggests that they understand the basic principle of noun-noun compounding at quite an early age, if compounding is productive in their input (Clark, I993). However, there is some evidence to suggest that understanding the basic principle of compounding does not necessarily mean that children parse all the compounds they already know. For example, Berko (r958) examined the ability of English-speaking children (four to seven) to parse existing compounds like birthday and found that especially younger children in her study had difficulties explaining compounds. Children usually mentioned a major function or a salient feature of the compound instead of relating the constituents with each other. Note, however, that about half of her experimental items were partially opaque and posed problems even for adults (e.g. Friday, handkerchief). Nevertheless, it seems that even children as old as 4; 0 to 7; 0 may have some difficulty parsing existing compounds, in spite of the fact that they understand and use novel compounds much earlier. Why might this be? Part of the answer may come from research on adults' processing of compounds.

For adults, the main interest in compounds has been for their access and storage in the mental lexicon. For this reason, the focus of research has mainly been on the processing of visually presented compounds. Various frequency measures appear to affect the ease of access. Firstly, higher frequency compounds are recognized faster (Van Jaarsveld \& Rattink, I 988; De Jong, Feldman, Schreuder, Pastizzo \& Baayen, 2002). Secondly, the size of the modifier constituent family, i.e. the number of compounds sharing the modifier with the target compound, affects compound processing. For 
example, the modifier constituent family of beanbag includes beanstalk, beanpole, bean soup, and bean burrito etc. In a visual lexical decision experiment, participants recognized English phrasal compounds, i.e. compounds written as two words, faster when the modifier had a large family size than when it had a small family size (De Jong et al., 2002). Modifier families also influence sense-nonsense decisions of novel compounds (Gagné \& Krott, 2004) and the creation of novel compounds in Dutch and German (Krott, Baayen \& Schreuder, 200I; Krott, Schreuder \& Baayen, 2002; Krott, Schreuder, Baayen \& Dressler, 2004). The effect of the family size has been explained by (co-)activation of the constituent family members during the processing of the target compound (for a discussion of the storage of semantic relations see Gagné \& Spalding, 2004).

But not only the family size (a type count), also the summed frequency of all members of a family, the family frequency (a token count), plays a role in accessing known compounds. The modifier family frequency, together with compound frequency, appears to determine response times in a lexical decision experiment with English and Dutch compounds that are written as single words (De Jong et al., 2002; Gagné \& Krott, 2004). Although family size and family frequency are two measures that are highly correlated, De Jong et al. (2002) have shown that both measures independently affect reaction times.

There is evidence that constituent families are not only important for adults but already for preschool children. Neijt, Krebbers \& Fikkert (2002) showed in post hoc analyses of a compound production experiment that Dutch-speaking four-year-olds are partly guided by constituent families when they create novel compounds. Dutch compounds often contain interfixes (e.g. -s- and -en- in schaap $+s+$ hond 'sheepdog' and schaa$\mathrm{p}+\mathrm{en}+\mathrm{kaas}$ 'sheep cheese'). It appears that the choice of interfix for a novel compound (e.g. -en- for banaan + ? + soep 'banana soup') can partly be predicted by the distribution of interfixes in familiar compounds (banaan + en + schil 'banana peel', banaan $+e n+i j s$ 'banana ice cream', etc.).

The purpose of the present study is to see whether constituent families affect preschool children's processing of familiar English compounds. We will focus on the question of whether children's realization that a compound is a combination of two existing word parts is enhanced by their knowledge of other compounds with the same parts. We chose to examine children's processing of familiar rather than of novel compounds because we are interested in how the knowledge of morphologically complex words (here noun-noun compounds) leads to morphological awareness, which can change the understanding of already acquired words. Given the assumption that early compounds of a child's vocabulary (such as the ones used in our study) are acquired as whole units without internal structure, the knowledge 
of compounds that are similar in form and meaning, i.e. compounds belonging to a constituent family, can make the child aware of the compounds' internal structure. In addition, drawing relations between the compounds of a constituent family might even change the child's interpretation of an already known compound. For example, one of the children in our study (age $3 ; 7$ ) explained the compound chocolate cake as something that indicates somebody is 'having a birthday'. Even if this answer did not reveal the child's full understanding of the word chocolate cake, it is likely that the child had not realized that a chocolate cake is always a cake made out of chocolate. Assuming that this interpretation is correct, we can hypothesize that once this child has realized that there are other words with chocolate and that all these words have something to do with chocolate, the child might realize that a chocolate cake is always made out of chocolate. Thus, a child might arrive at a different understanding of a compound when knowing other, similar compounds.

In this study we asked children to explain the meaning of familiar noun-noun compound words, following Berko ( I 958) and Mellenius ( I 997). An explanation of a compound naturally contains the two constituents because compounding usually serves a subcategorization function (Clark \& Berman, I987; Berman \& Clark, I 989). That is, the higher-level category appears as the head of the compound, while the modifier refers to a feature of the subordinate category that distinguishes the compound from other subordinate categories. For example, an apple tree is a tree that produces apples and not plums, cherries, lemons, etc. Importantly, the meaning of a compound is fully captured by the meaning of the higher category (the head), the distinguishing feature of the subcategory (the modifier), and the relation between both constituents (an apple tree is a tree with apples). Note that in contrast to the head and modifier, the relation is not overtly expressed. Given this structure, the most straightforward way of explaining a compound is to name both head and modifier and to state the relation between them. The dependent measure in this study is therefore whether the child explicitly (or implicitly) mentions the head or the modifier.

Note that we did not necessarily expect a correct definition or a correct relation. The failure to mention the parts and the semantic relation could have different reasons. First, a child might not have decomposed a compound into its constituents. In this case, one expects the child to mention a major function or a salient feature of the compound as in Berko's experiment. Second, a child might have recognized only one of the two constituents. For example, if the child recognizes day in birthday but does not know what birth is, the child might reject the possibility that birthday is a compound and therefore mentions a major function or a salient feature instead. Alternatively, the child might only mention day. Third, a child might have recognized both parts of the compound without being able to 
relate the two constituents. In this case, she might decide not to mention the constituents. Therefore, not mentioning a constituent does not necessarily mean that the compound has not been correctly segmented.

Apart from the family size, we also tested whether there was any additional effect of the frequency of a compound, the frequency of the compound constituents when used as independent words, or the family frequency. The frequency of the compound estimates how familiar children are with the compound. Children might be more likely to explain compounds that are more familiar to them because they have a better knowledge of what those compounds mean. The frequency of the constituents might influence the ease with which children recognize the constituents of a compound. A higher frequency can, for instance, mean that the children are more familiar with possible variations in pronunciation and can more easily pick out the word from the speech stream. Last but not least, family frequency provides a probability measure for a word to be a head or modifier of a compound. Thus, a high family frequency means that a word is more likely to be a compound constituent.

\section{METHODS}

\section{Participants}

Twenty-five English-speaking children took part in this study. Two children were excluded from the sample because they were bilingual and another one had to be left out because information about her knowledge of compounds (see questionnaire below) was not available. The following analyses are therefore based on 22 children aged $3 ; 7$ to $5 ; 9$ (mean age 4; ro, S.D. ०;8).

\section{Procedure}

The children were introduced to a puppet named Mork by a native speaker of English. The researcher told the children that Mork came from another planet, that he did not speak English very well and that he was interested in why we used some words. She provided the example of 'blueberries', saying 'We say blueberries because they are berries that are blue'. We decided not to use a noun-noun compound as an example so that it was not possible for the children to repeat the semantic relation of the example compound for all experimental compounds. The purpose of the example was rather to show that a compound can be split up into two parts that are related to each other. The experimenter asked the children to explain to Mork 25 nounnoun compound words, the components of which had either high family size or low family size (see Table I). The experimenter elicited the children's explanations by having Mork ask 'Why do we say ?' before each 
KROTT \& NICOLADIS

TABLE I. Stimuli by family size (High or Low) of modifiers and heads

\begin{tabular}{llll}
\hline High-High & High-Low & Low-High & Low-Low \\
\hline baby book & apple core & cardboard box & apron strings \\
car door & bookshelf & crayon box & breakfast cereal \\
cheese sandwich & paper napkin & grapefruit juice & duck feet \\
chocolate cake & snow fort & hospital bed & heat rash \\
cornbread & water pistol & popsicle stick & peanut butter \\
fruit basket & waterslide & roof rack & $\begin{array}{l}\text { power tools } \\
\text { stepladder }\end{array}$ \\
\hline
\end{tabular}

item in Table I. The children's responses were tape-recorded and all speech relevant to the task was transcribed.

\section{Materials}

Because the number of compounds that preschool children know is rather small and most of the compounds they know do not have a large family, the set of possible experimental items is restricted. Furthermore, we wanted to restrict the compounds we selected to those in which each constituent plays a transparent role in the meaning and each constituent was a concrete word children might know. The stimuli that we selected are listed in Table $\mathrm{I}$. Note that there were equal numbers in each category except for the low family size modifier-low family size head category. We included an extra item here because we were concerned that children might not know the constituents of these compounds. Four items contained a compound word as the modifier (e.g. breakfast cereal and grapefruit juice). All of these compounds, though, are semantically opaque. We included them because even adults do not always see the underlying structure of opaque compounds (Elliot, I 997).

To determine the modifier families and head families of the target compounds, we first gathered all noun-noun compounds available in the CELEX lexical database (Baayen, Piepenbrock \& Gulikers, I995). This database was constructed from adult language, so we modified the compound list to only include compounds children were likely to hear. Two native English speakers, both trained in psycholinguistics and with extensive experience with children, went through the database, adding and deleting words according to what they thought children might know.

\section{Parental checklist of compounds children know}

To verify the families of the compounds in Table I, we asked parents to check off the words their children knew well enough to say spontaneously 
TA B LE 2. Family members for chocolate cake on parental checklist

\begin{tabular}{|c|c|}
\hline chocolate & cake \\
\hline chocolate bar & angelfood cake \\
\hline chocolate brownie & carrot cake \\
\hline chocolate candy & coffee cake \\
\hline chocolate chips & cupcake \\
\hline chocolate chip cookie & ice cream cake \\
\hline chocolate cookie & onion cake \\
\hline chocolate ice cream & pattycake \\
\hline chocolate icing & plum cake \\
\hline chocolate milk & pound cake \\
\hline chocolate mousse & rice cake \\
\hline chocolate muffin & strawberry cake \\
\hline chocolate pudding & wedding cake \\
\hline
\end{tabular}

from a list of 276 compounds plus the 48 different monomorphemic words needed to make the compounds in Table I. For example, chocolate cake was one of our target words in the study and we listed chocolate, cake, and chocolate cake. For the family members, see Table 2 . The checklist was sent out with permission slips and filled out by parents before their children participated in the study. Note that a parent's 'no' on this checklist can mean two things: (I) the child indeed did not know the compound or (2) the parent quickly went through the checklist and checked off only those compounds of which he/she was absolutely sure that the child knows. Therefore, our measure of family size might underestimate the actual family size. However, there is no reason to assume that the division in high and low family size compounds is affected by this measurement.

The parents of $2 \mathrm{I}$ children sent back a completed checklist. We used these data to calculate whether the children knew the compounds in Table I and the constituents prior to this experiment. We based any calculations only on the compounds for which we had a response. So, for 2 I children, parents could have given a total of 525 responses (based on the 25 compounds in Table I) and in fact they gave 472 responses. Out of those 472 compounds, the parents reported that children knew $85 \%(N=399)$ of their modifiers (e.g. chocolate) and $76 \%(N=359)$ of their heads (e.g. cake). However, the children knew only $47 \%(N=220)$ of our target compounds (e.g. chocolate cake; in Table I) according to parental report. Because it was possible that the children were not familiar with some of our target words, it is important to take this into account in our analyses.

We checked the family sizes of our target words on the basis of the parental report. Table 3 summarizes the average family size for the experimental sets of Table I, i.e. the average number of other compounds from the same family on the checklist that parents indicated their children knew. 
TABLE 3. Average family size (standard deviation) of modifiers and heads in experimental sets (modifier family size-head family size) according to parental report

\begin{tabular}{lllll}
\hline & High-High & High-Low & Low-High & Low-Low \\
\hline modifiers & $3.86(3.58)$ & $3.53(3.86)$ & 0.1 I (0.3 I $)$ & $0.42(0.67)$ \\
heads & $3.59(2.76)$ & $0.01(0.09)$ & $4.3(4.06)$ & $0.06(0.24)$ \\
\hline
\end{tabular}

As can be seen in Table 3, the family sizes according to parental report corresponded quite nicely to our a priori classifications.

\section{Scoring children's responses}

The responses that children had given in the experiment were scored independently by both authors, and any differences were resolved by discussion. Because we were interested in whether a child mentioned the modifier and/or the head of a compound, we scored modifiers and heads separately, leading to two dependent variables (modifier score and head score). The children's responses were given full marks for a constituent (i.e. 2) if they explicitly mentioned the constituent. For example, to explain paper napkin, one child said 'It's made out of paper and it's a kind of napkin'. This response was scored as 2 marks for the modifier and 2 marks for the head. Children's responses were awarded partial marks for a constituent (i.e. I) when the constituent was implicitly mentioned. For example, to explain power tools, one child said 'Drills are power tools! It's because they're run by electricity'. We thought that the use of the word electricity implied power and the use of the word drills implied tools, so this response was scored as I point for the modifier and I point for the head. Children's responses were given zero points for a constituent when it was mentioned neither explicitly nor implicitly.

It should be noted that this scoring scheme probably underestimates children's knowledge of the meaning of the compound words as wholes. For example, one child said 'It's all white and it has paper lined on it' to explain hospital bed. This child was clearly describing the kind of bed one finds in a doctor's examining room. However, because we were interested in whether the children segmented a compound and not just in whether they know the compound's meaning, this response was scored as o for both the modifier and head.

In some instances, children's explanation of compounds suggested that they may not have understood the usual interpretation of the semantic relations of the compounds. For example, in explaining chocolate cake, one child said 'A cake with chocolate icing on it'. This response was given

$$
\text { I } 46
$$


I point for the modifier (because the child clearly knew that there was something chocolate on the cake) and 2 points for the head. This high score was obtained even though the child was incorrect about the semantic relationship between chocolate and cake. While we did not systematically examine the children's understanding of the semantic relationships, it appeared that the children usually used the correct semantic relationship. They tended to make mistakes mostly on chocolate cake and stepladder. The latter they interpreted as a ladder for stepping on rather than a ladder with steps.

\section{Frequency}

We estimated the children's familiarity with the compounds used in our experiment by determining their frequency in all English transcripts in the CHILDES database (MacWhinney, 2000). We counted the occurrences in both the adult and the child speech. Similarly, we estimated the children's familiarity with the compound constituents by calculating their frequency in CHILDES. Note that our calculations underestimate the frequency since all words are only counted in their singular form. In contrast, the calculations slightly overestimate the frequency of the constituents since they do not distinguish between occurrences as independent nouns and as compound constituents.

\section{RESULTS}

As this study is the first to test the effect of constituent families on preschool children's processing of familiar compounds, we will start with an overall analysis, treating the children as a group. We will then focus on whether the effect of family size changes with age and whether other variables, such as the frequency of a compound might be an additional or even better predictor of the children's performance.

\section{Family size effects}

Figure I summarizes the scores for modifiers and heads for high and low family sizes for the children as a group. Overall, children's scores for modifiers (mean $\mathrm{I} \cdot 2$ ) were higher than the ones for heads (mean 0.8 ; $t(94 \mathrm{I})=6 \cdot 6, p<0.00 \mathrm{I})$. This low score for heads has at least two possible reasons. First, as mentioned before, according to the parental reports, the heads were less familiar $(76 \%)$ than the modifiers $(85 \%)$. Second, children often referred to the head with the pronoun $i t$, as in 'because there's cheese in it' when explaining cheese sandwich. Because the heads are not mentioned in these cases, we gave them a score of zero. Note that we are 


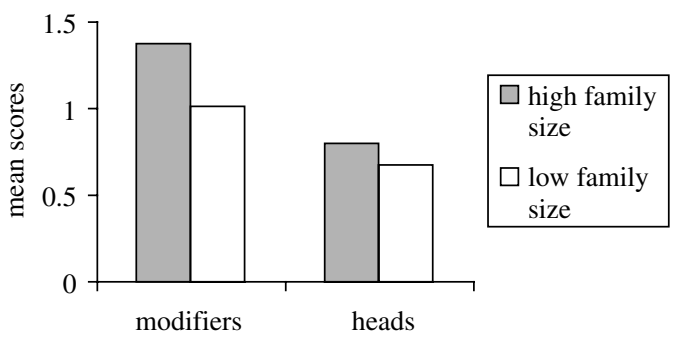

Fig. I. Children's mean scores for modifiers and heads by family size (high vs. low).

interested in whether the children have recognized the head correctly, and the pronoun is not informative enough to determine whether they did. We have to keep in mind that the head scores might underestimate the ability to segment compounds to a larger degree than the modifier scores do.

As already mentioned, some of the compounds that we used in our study are made up of three nouns instead of two nouns, i.e. the modifiers themselves were noun-noun compounds (e.g. grapefruit juice and cardboard box). One might assume that these compounds are more difficult to explain because they have to be split into the correct main constituents (grapefruit and juice, not grape and fruit juice). However, when comparing the children's scores for these compounds with those for other compounds of the same categories ( $\mathrm{LH}$ and LL), it turns out that they are not unusual at all. Thus, either the children had not realized that the compounds consist of three parts, or they had used other information. They might, for instance, have known that grapefruit juice is made from grapefruits and not from grapes.

In order to test whether the factors 'modifier family size' and 'head family size' affected the scores for modifiers and heads, we analysed the scores of modifiers and heads separately. We conducted two (2) modifier family size $\times(2)$ head family size ANOVAs for the dependent variable 'score for modifiers': one on the mean scores by subjects (see $F_{I}$ ) and one on the mean scores by items (see $F_{2}$ ). In both analyses, there was a significant main effect of the modifier family size $\left(F_{I}(\mathrm{I}, 84)=\mathrm{I0} 3, p<0.0 \mathrm{I}\right.$; $\left.F_{2}(\mathrm{I}, 2 \mathrm{I})=4.57, p<0.05\right)$, but no effect of the head family size $\left(F_{I}(\mathrm{I}, 84)<\mathrm{I}\right.$; $\left.F_{2}(\mathrm{I}, 2 \mathrm{I})<\mathrm{I}\right)$, and no interaction of the two family sizes $\left(F_{I}(\mathrm{I}, 84)=\mathrm{I} \cdot 3\right.$, $\left.p>0.05 ; F_{2}(\mathrm{I}, 2 \mathrm{I})<\mathrm{I}\right)$. Thus, modifier scores were affected only by the modifier family size, with higher scores for higher family sizes. As for head scores, we also conducted two (2) modifier family size $\times(2)$ head family size ANOVAs for the dependent variable 'score for heads': one on the mean scores by subjects and one on the mean scores by items. In contrast to the results for modifier scores, there were no effects of the modifier family size $\left(F_{I}(\mathrm{I}, 84)<\mathrm{I} ; \quad F_{2}(\mathrm{I}, 2 \mathrm{I})<\mathrm{I}\right)$ nor the head family size $\left(F_{I}(\mathrm{I}, 84)=\mathrm{I} \cdot 6\right.$, $\left.p>0.05 ; F_{2}(\mathrm{I}, 2 \mathrm{I})=\mathrm{I} \cdot 4, p>0.05\right)$ on scores for heads, nor an interaction 
between the two factors $\left(F_{I}(\mathrm{I}, 84)=2 \cdot \mathrm{I}, p>0.05 ; F_{2}(\mathrm{I}, 2 \mathrm{I})=2 \cdot \mathrm{I}, p>0.05\right)$. Taking together the results for both constituents, we conclude that family size affects children's scores for modifiers, but not for heads. Furthermore, the family of one of the two constituents does not affect the scores of the other constituent, and the two factors modifier family size and head family size do not interact. In other words, there is no effect that crosses the constituent boundary. This was the case for all further tests. In what follows, we will therefore only report analyses that test the effect of the modifier family size for modifiers and the effect of the head family size for heads. For these analyses we calculated the following scores. For analyses of modifier scores, we collapsed the scores of the conditions high and low head family size. Similarly, for analyses of head scores, we collapsed the scores of the conditions high and low modifier family size.

\section{Age}

Because we expected the older children in our study to have a larger vocabulary size and consequently to know more compounds, we suspected that the effect of family size might be more prominent in the responses of older children. In order to test this, we conducted an ANCOVA with modifier family size as main factor, age (i.e. number of months) as a covariant, and modifier scores as dependent variable. However, there was no main effect of age $\left(F_{2}(\mathrm{I}, 84)<\mathrm{I}\right)$ and no interaction of modifier family size and age $\left(F_{2}(\mathrm{I}, 84)<\mathrm{I}\right)$. Similarly, when conducting an ANCOVA with head family size as main factor, age as covariant, and head scores as dependent variable, there was no main effect of age $\left(F_{2}(\mathrm{I}, 84)<\mathrm{I}\right)$ and no interaction of head family size and age $\left(F_{2}(\mathrm{I}, 84)<\mathrm{I}\right)$. These results suggest that the children's performance does not change with age. In order to further verify this, we split the children into groups of three ( 2 children), four (8 children), and five-year olds ( 22 children). Because only two three-yearolds had taken part in our experiment, we will restrict our discussion to four and five-year-olds. The upper panels of Figure 2 show the results for modifiers and heads for these two age groups. Although five-year-olds appear to have slightly higher scores (mean modifier score: $1 \cdot 3$; mean head score: 0.8 ) than four-year-olds (mean modifier score: I·०; mean head score: 0.7 ), the effects of modifier and head families are very similar. When comparing scores of modifiers with high families and scores of modifiers with low families, the two age groups both show effects of family size (fouryear-olds: $t_{I}(7)=3.4, \quad p<0.0 \mathrm{I} ; \quad t_{2}(23)=2.6, \quad p<0.0 \mathrm{I} ;$ five-year-olds : $t_{I}(\mathrm{II})=6 \cdot 0, p<0.00 \mathrm{I} ; t_{2}(23)=2 \cdot 2, p<0.05$; all $t$-tests in this study are onetailed). In contrast, when comparing scores of heads with high families and scores of heads with low families, neither age group shows any effect of head family size (four-year-olds: $t_{I}(7)=\mathrm{I} \cdot 2, \quad p>0 \cdot 05 ; \quad t_{2}(23)=\mathrm{I} \cdot 4$, 
four-year-olds

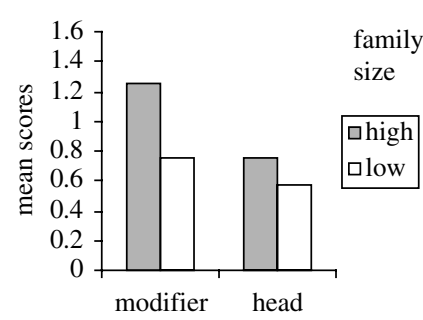

children do not know compounds

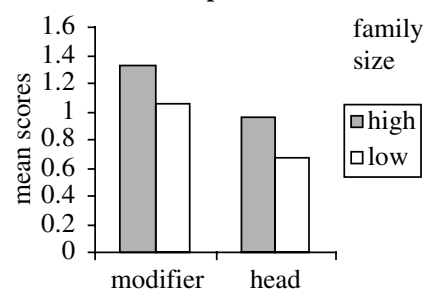

five-year-olds

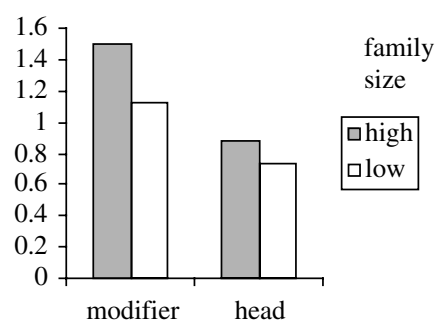

children knew compounds

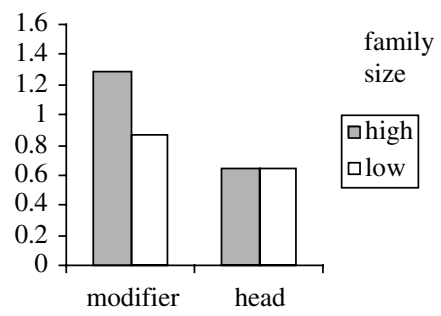

Fig. 2. Mean scores for modifiers and heads by family size (high vs. low) for four and five-year-olds (upper panels) as well as compounds that children know and do not know (lower panels).

$p>0.05$; five-year-olds: $\left.t_{I}(\mathrm{I} \mathrm{I})=\mathrm{I}_{5}, p>0.05 ; t_{2}(23)=\mathrm{I} \cdot \mathrm{I}, p>0.05\right)$. These results confirm that the two age groups do not differ.

\section{Frequency effects}

In post hoc analyses we focused on additional effects of compound frequency, frequency of the constituent, and constituent family frequency on the children's scores. We will first discuss the results for the children as a group and then look at four and five-year-olds separately.

A by-item covariance analysis of all children's scores for modifiers revealed no effects of any of the tested frequency measures (i.e. compound frequency, modifier frequency, and modifier family frequency). In the case of the head scores, however, there were main effects of head family size $\left(F_{2}(\mathrm{I}, \mathrm{I} 7)=6 \cdot 9, p=0.02\right)$ and head frequency $\left(F_{2}(\mathrm{I}, \mathrm{I} 7)=\mathrm{I} 4 \cdot 2, p=0.002\right)$, indicating that higher scores were obtained for higher family sizes of the heads and higher frequency heads. In addition, there were a number of interactions. There was a marginally significant interaction of head family size by head frequency $\left(F_{2}(\mathrm{I}, \mathrm{I} 7)=4.5, p<0.05\right)$, which means that scores tend to be higher for heads when both family size and frequency are high. There were also interactions of head family size with head family frequency 
$\left(F_{2}(\mathrm{I}, \mathrm{I} 7)=\mathrm{I} 2 \cdot 8, p=0.002\right)$ as well as head family size with head family frequency and head frequency $\left(F_{2}(\mathrm{I}, \mathrm{I} 7)=\mathrm{I} \mathrm{I} \cdot 3, p=0.004\right)$, indicating that the highest scores are obtained for combinations of very frequent heads, large families, and high frequency family members. Interestingly, in this and all other analyses reported below, compound frequency did not have an effect on the children's scores. Thus, familiarity with the compound did not seem to facilitate segmentation. Note further that we now have evidence for an effect of family size on the scores for heads that we had not found when testing a simpler statistical model that did not contain head frequency and head family frequency.

In summary, the use of modifiers was only affected by the modifier family size, not by compound frequency, the frequency of the modifier, or the frequency of the modifier family members. As for the heads, children were more likely to include the head in their explanations when the head occurs in a lot of compounds (i.e. in case of a large head family) and when the head is a familiar noun. This effect increases when, in addition, the family members of the head family are high frequency nouns too.

A comparison of four and five-year-olds with respect to frequency measures revealed that neither of the groups shows an effect of any of the frequency measures on modifier scores. As for the heads, the two age groups slightly differ from each other. Both groups showed effects of head frequency (four-year-olds: $F_{2}(\mathrm{I}, 2 \mathrm{I})=5 \cdot 4, p<0 \cdot 05$; five-year-olds: $F_{2}(\mathrm{I}, \mathrm{I} 7)=$ $9 \cdot 0, p<0.0 \mathrm{I})$, indicating that higher frequency heads are mentioned more often. But only five-year-olds showed an effect of head family size $\left(F_{2}(\mathrm{I}, \mathrm{I} 7)=4 \cdot 7, p<0.05\right)$ and an interaction of head family size and head family frequency $\left(F_{2}(\mathrm{I}, \mathrm{I} 7)=5 \cdot 2, p<0 \cdot 05\right)$ as well as a three-way interaction of head family size, head family frequency, and frequency of the head $\left(F_{2}\left(\mathrm{I}, \mathrm{I}_{7}\right)=4 \cdot 8, p<0.05\right)$.

We have seen that four and five-year-olds do not differ from each other with respect to the factors that determine their scores for modifiers. Both age groups are affected by modifier family size. We conclude that even fouryear-olds used constituent families when segmenting compounds. In contrast, an effect of the head family size was evident only for five-year-olds. One might assume that five-year-olds mentioned the heads more often because they had a better understanding of the task. However, this is not the case since the average head scores for four and five-year-olds did not differ $\left(t_{I}(38)<\mathrm{I}\right)$. We therefore assume that the head family size affects children's explanations as the number of compounds they know increases.

\section{Children's knowledge of compounds}

In our analyses so far, we have not taken into account that not all the children knew the compounds that they had to explain. Recall that the parents 
reported that their children only knew $47 \%$ of our target words well enough to say spontaneously. It might be the case that compound families only affect the explanations of unknown compounds, since known compounds can be explained without knowing similar compounds, while unknown compounds can only be understood by analogy to existing compounds. In what follows, we will present separate analyses for known and unknown compounds according to parental report.

Let us first look at the results for unknown compounds in the lower left panel of Figure 2. For scores both of modifiers and of heads, there were significant main effects of family size (modifiers: $t_{2}(23)=\mathrm{I} \cdot 9, p<0 \cdot 05$, but see subject analysis: $t_{I}(67)=\mathrm{I} \cdot 2, p>0.05$; heads: $t_{2}(23)=2 \cdot 0, p<0.05$; $\left.t_{I}(67)=\mathrm{I} \cdot 75, p<0.05\right)$. As before, there were no effects of any frequency measure on the scores for modifiers, but there were frequency effects on the head: There was a main effect of head frequency $\left(F_{2}(\mathrm{I}, \mathrm{I} 7)=2 \mathrm{I} \cdot 8\right.$, $p<0.00 \mathrm{I})$, an interaction between head family size and head frequency $\left(F_{2}(\mathrm{I}, \mathrm{I} 7)=\mathrm{II} \cdot 0, p<0 \cdot 0 \mathrm{I}\right)$, an interaction between head family size and head family frequency $\left(F_{2}(\mathrm{I}, \mathrm{I} 7)=7 \cdot 7, p<0.05\right)$ as well as a three-way interaction between family size, head frequency, and head family frequency $\left(F_{2}(\mathrm{I}, \mathrm{I} 7)=6 \cdot 9, p<0 \cdot 05\right)$.

Constituent families clearly helped children to segment unknown compounds. Was this also true of known compounds? The lower right panel of Figure 2 shows the result for known compounds, averaged over items. The results for modifiers did not differ from the ones obtained for unknown compounds: There was a main effect of family size only in a by-item analysis $\left(t_{I}(64)=\mathrm{I} \cdot 5, p>0.05 ; t_{2}(23)=2 \cdot \mathrm{I}, p<0.05\right)$, and no effect of any frequency measures. Like for unknown compounds, there was an effect of the head frequency on the head scores $\left(F_{2}(\mathrm{I}, 2 \mathrm{I})=\mathrm{I}_{0} \cdot 5, p<0.0 \mathrm{I}\right)$. In contrast to unknown compounds, though, there was no effect of head family size on head scores $\left(F_{\mathrm{I}}(\mathrm{I}, 64)=<\mathrm{I} ; F_{2}(\mathrm{I}, 2 \mathrm{I})=\mathrm{I} \cdot 3, p>0 \cdot 05\right)$.

Interestingly, both the explanations of known and unknown compounds were affected by family size of modifiers as well as by the familiarity with the heads (i.e. head frequency).

\section{Children's knowledge of constituents}

Recall that there were a number of compound constituents that the parents reported the children did not know as independent words. We checked whether family size might be confounded with the knowledge of the constituents and found that, according to the parental report, children indeed know more modifiers that occur in families with high family sizes than modifiers that occur in families with low family sizes $\left(t_{I}(\mathrm{I} 7)=2 \cdot 3\right.$, $p<0.05)$. There was no such difference, though, for heads $\left(t_{I}(\mathrm{I} 7)<\mathrm{I}\right)$. Given this result, the question arises whether the knowledge of the modifier 
is the true factor affecting children's scores for modifiers. To answer this question we conducted an analysis restricted to the compounds of which children knew the modifiers. If family size still has an effect within this set of responses, we can conclude that, although the knowledge of the modifiers might be one of the factors affecting the scores, family size also affects the scores.

When the children knew the modifiers as independent words, the mean scores for modifiers in compounds with high family sizes were higher (mean across items: $1 \cdot 4$ ) than those for compounds with low family sizes $\left(\mathrm{I} \cdot \mathrm{I} ; t_{I}(75)=\mathrm{I} \cdot 7, p<0.05 ; t_{2}(23)=\mathrm{I} \cdot 7, p<0 \cdot 05\right)$. There were no effects of any frequency measure. In short, it is not solely the knowledge of the modifiers that determined whether the modifiers were mentioned in our experiment.

\section{SUMMARY AND DISCUSSION}

The aim of this study was to test whether family size affects children's segmentation of already known compounds. The analyses of our experiment showed that children were more likely to mention modifiers of compounds with large family sizes than small family sizes. This was true, independent of whether the children knew the compounds or not. There was no difference between four-year-olds and five-year-olds, suggesting that modifier families are active as soon as they exist. While there was always a family size effect, we never found that the familiarity with the modifier or the members of the modifier family led to higher scores.

In contrast to modifiers, the scores for heads showed a less robust effect of family size. That is, the family size effect was more evident for unknown compounds than for known compounds. Four-year-olds did not show any effect at all, while there was evidence for an effect for five-year-olds. In contrast to the lack of any frequency effect on modifiers, there was a robust effect of the constituent frequency on scores for heads. Thus, the children were more likely to mention the head if they were familiar with it as an independent word. This likelihood increased when the compounds sharing the head were very frequent, i.e. when there was a high probability that the noun was a head of a compound.

We conclude that family size does affect preschool children's compound processing. Naturally, this conclusion is limited to the methodology we used in the present study. We do not know what kinds of cognitive abilities are required to explain a compound in the way we have required here. And this task was difficult for some of the younger children. Even so, there were surprisingly few differences between the four-year-olds and five-year-olds. With a more sensitive task, perhaps one that was easier for younger children, greater age differences might be revealed. 
Assuming our conclusion is correct, the question arises: why are modifiers more robustly affected by family size than heads? In the following discussion, we explore several possible answers to this question.

If we assume that a larger family has a stronger effect, the family size for modifiers in our experiment might be on average larger than that for heads. However, as Table 3 shows, the average family size for modifiers is even slightly lower than that for heads. In addition, the contrast of high vs. low family size is bigger for heads than for modifiers, suggesting that, in contrast to our findings, the effect of the heads should be stronger than the one for modifiers. We conclude that differences in family size can be ruled out as an explanation for the differences between head and modifier scores.

Another possible factor that might influence the results of the experiment is the semantic relation between the modifier and head. There are two ways in which the semantic relation of the presented compound might play a role. First, it could matter whether the semantic relation is common for the compounds in the children's lexicon as a whole. Mellenius (i 997) proposed for Swedish compounds that there might be a hierarchy of semantic relations. However, in an experiment in which she asked six-to-nine-year olds to explain Swedish novel compounds, children did not show any preference for a particular relation. Second, the semantic relations of the modifier family might affect the ease with which children explain compounds. Take, for instance, chocolate cake, a compound with a large modifier family: all family members (see also Table 2) contain the relation MADE-OF. Due to a single possible relation for chocolate it might have been easier for the children to explain chocolate cake and therefore to correctly mention the two constituents. Note, though, that this explanation does not hold for all compounds with a large modifier family. The modifier family of fruit basket (a basket FOR fruit), for example, contains two relations: FOR (e.g. fruit bowl) and MADE-OF (e.g. fruit salad; exception: fruit fly). The relation contained in the target compound (FOR), though, hardly occurs in the compounds that children know according to parental report (on average in 0.6 compounds), while they do know a number of compounds with MADE-OF (on average $2 \cdot 3$ compounds). Despite the lack of knowledge of other compounds with the same relation, all children who gave an explanation of fruit basket mentioned both constituents. This renders the distribution of semantic relations of modifier families a rather unlikely factor, and, more importantly, it suggests that the factor family size is (at least) theoretically independent from a factor 'distribution of semantic relations in constituent families'.

A further possible factor is word stress. Compounds in English usually have compound stress, which means that the modifier receives the primary stress. Compound stress might lead the attention to the modifier and 
away from the head. We therefore asked 5 adult Canadian native speakers to pronounce the compounds. The results showed that most of the compounds that we had used in our experiment ( 8 out of 25) are indeed stressed on the modifier, while four were stressed on the head, and three were stressed inconsistently. Thus, compound stress could explain why children focused more on the modifiers.

While we cannot rule out the stress pattern of the compounds as an explanation for our finding that modifiers were more robustly affected by family size than heads, the semantic role of the modifier seems a more likely explanation. Both in studies with adults and children, the modifier and modifier family appear to play a more important role than the head and the head family. In the case of a lexical decision experiment with adults, De Jong et al. (2002) have found family size and family frequency effects only for modifiers, not for heads. In a study on the selection of interfixes for novel Dutch compounds, modifier families are much better predictors for the selection than head families (Krott et al., 200I ; Krott et al., 2002; Krott et al., 2004). Furthermore, lexical decisions to novel English compounds can be primed by compounds with the same modifier and the same relation (Gagné \& Spalding, 2004), and the ease of interpreting these compounds is more strongly influenced by the possible semantic role of the modifier than of the head (e.g. Gagné \& Shoben, I 997). In the case of compound acquisition, studies in which children had to pick the corresponding picture for a novel compound revealed that the most common mistake for younger children was to pick the picture for the modifier, independent of whether the language has right-headed or left-headed compounds (Clark et al., I985; Berman \& Clark, I989; Mellenius, I 997).

Taken together, these studies rather show an effect of the modifier than of the head. This might be due to the way compounds are processed, with modifiers playing a relatively more important role than heads. This statement might seem counterintuitive given that the head is the constituent that specifies the semantic category of the compound and often the grammatical category as well. One might therefore expect the head to be more important. However, as mentioned before, compounds are used to name subcategories and, at the same time, to distinguish a particular subcategory from others. Therefore, the modifier, i.e. the constituent that establishes the distinguishing feature, can become more important than the head. A modifier effect has been shown for languages with both right-headed compounding (English and Dutch) and left-headed compounding (French: Turco, 2000; Hebrew: Berman \& Clark, I989). Thus we cannot conclude with certainty whether the effect found in our study is a modifier or a left-most element effect. To test the idea that the modifier is important, it would be interesting to see if the effect found here holds in languages with left-headed compounds like French and Hebrew. 
The question of what causes the differences between family size effects for heads and modifiers has to be addressed in more detail in further research. The important result of this study, though, is that children's segmentation of familiar compounds is influenced by the knowledge of other compounds. In terms of models that have been developed for compound processing by adults, one can understand this effect as follows.

Effects of family size in adult studies have been explained by a model of compound storage in which compound representations are linked to representations of their constituents (e.g. Krott et al., 2002; see also Libben, I998). The members of a constituent family are assumed to be linked via the shared constituent and possibly also via their overlapping semantics. The facilitation effect of a larger family on response latencies in, for instance, lexical decision tasks has been explained by co-activation of the interconnected family members (De Jong, Schreuder \& Baayen, 2000). Children acquiring compounds, though, have yet to build up these connections. They first have to recognize the internal morphological structure of a compound before the compound representation can be linked to the constituents. The effect of family size in our experiment suggests that the recognition of the internal structure is enhanced by the knowledge of various other compounds sharing the modifier (and the head) with the compound in question. We therefore assume that family members are already connected and co-activated in a way similar to the one in the adult studies. What our study cannot reveal, though, is whether the compounds that the children had to explain are already stored with connections to their constituents. The children might have segmented them during the experiment for the first time. What the results do suggest, though, is that children's acquisition of compounds may be facilitated by the knowledge of other similar compounds. In this study, we had chosen to examine familiar compounds. We assume, though, that our findings are not restricted to familiar compounds, but that family size is also important for the parsing of novel compounds.

The results of this study also add to the general understanding of the role of similarity in the acquisition of morphology. Our study suggests that morphological structure might only be recognized when there are structurally similar words available that can serve as an analogical basis. Knowledge of the nouns in head position was related to children's use in our experiment. The knowledge of a considerable number of other complex words of the same structural pattern and with overlapping morphemes appears to play a major role. The influence of the family size resembles the influence of type frequency that has been reported for a different area of morphology acquisition: word formation. It has been argued that the type frequency of inflectional and derivational suffixes, not their token frequency is important for their productivity in child language (see e.g. Clark, I993). 
Thus, the effect of family size confirms the importance of type frequency for the acquisition of morphology.

\section{REFERENCES}

Baayen, R. H., Piepenbrock, R. \& Gullikers, L. (I995). The CELEX Lexical Database (CD$R O M)$. Linguistics Data Consortium, University of Pennsylvania: Philadelphia, PA.

Becker, J. A. (I994). 'Sneak-shoes', 'sworders' and 'nose-beards': a case study of lexical innovation. First Language 14, I95-2 I I.

Berko, S. (1958). The child's learning of English morphology. Word 14, I 50-77.

Berman, R. A. \& Clark, E. V. ( 1989 ). Learning to use compounds for contrast: data from Hebrew. First Language 9, 247-70.

Clark, E. V. (I98I). Lexical innovations: how children learn to create new words. In W. Deutsch (ed.), The child's construction of language. London: Academic Press.

Clark, E. V. (I983). Meanings and concepts. In P. H. Mussen (series ed.), L. H. Flavell \& E. M. Markman (vol. eds), Handbook of child psychology: vol. 3 Cognitive development. New York: Wiley.

Clark, E. V. (I 993). The lexicon in acquisition. Cambridge: CUP.

Clark, E. V. (1998). Lexical creativity in French-speaking children. Cahiers de Psychologie Cognitive I7, 513-30.

Clark, E. V. \& Berman, R. A. (1984). Structure and use in the acquisition of word formation. Language 6o, 542-90.

Clark, E. V. \& Berman, R. A. (1987). Types of linguistic knowledge: interpreting and producing compound nouns. Fournal of Child Language I4, 547-67.

Clark, E. V., Gelman, S. A. \& Lane, N. M. (1985). Compound nouns and category structure in young children. Child Development 56, 84-94.

De Jong, N. H., Feldman, L. B., Schreuder, R., Pastizzo, M. \& Baayen, R. H. (2002). The processing and representation of Dutch and English compounds: peripheral morphological and central orthographic effects. Brain and Language 81, 555-67.

De Jong, N. H., Schreuder, R. \& Baayen, R. H. (2000). The morphological family size effect and morphology. Language and Cognitive Processes 15(4/5), 329-65.

Elliot, D. (1997). The malleability of the adult mental lexicon. Unpublished BA Honours Thesis. University of Alberta.

Gagné, C. L. \& Krott, A. (2004). The interplay of relational availability, family size, and family frequency during the interpretation of noun-noun compounds. Manuscript in preparation.

Gagné, C. L. \& Shoben, E. J. (1997). Influences of thematic relations on the comprehension of modifier-noun combinations. Fournal of Experimental Psychology: Learning, Memory, and Cognition 23, $7 \mathrm{I}-87$.

Gagné, C. L. \& Spalding, T. L. (2004). Effect of relation availability on the interpretation and access of familiar noun-noun compounds. Brain and Language 9o, 478-86.

Krott, A., Baayen, R. H. \& Schreuder, R. (200I). Analogy in morphology: modeling the choice of linking morphemes in Dutch. Linguistics 39(I), $5 \mathrm{I}-93$.

Krott, A., Schreuder, R. \& Baayen, R. H. (2002). Linking elements in Dutch noun-noun compounds: constituent families as analogical predictors for response latencies. Brain and Language 8I $(\mathrm{I}-3), 723-35$.

Krott, A., Schreuder, R., Bayen, R. H. \& Dressler, W. U. (2004). Analogical effects on linking elements in German compounds. Manuscript submitted for publication.

Libben, G. (1998). Semantic transparency in the processing of compounds: consequences for representation, processing, and impairment. Brain and Language 6r, 30-44.

MacWhinney, B. (2000). The CHILDES project: tools for analyzing talk. Third edition. Mahwah, NJ : Erlbaum.

Mellenius, I. (1997). The acquisition of nominal compounding in Swedish. Lund: Lund University Press. 
Nicoladis, E. (2003). What compound nouns mean to preschool children. Brain and Language 84, 38-49.

Neijt, A., Krebbers, L. \& Fikkert, P. (2002). Rhythm and semantics in the selection of linking elements. In: H. Broekhuis \& P. Fikkert (eds), Linguistics in the Netherlands 2002. John Benjamins Publishing Company, Amsterdam/ Philadelphia, AVT Publications I 9 .

Turco, S. (2000). Determination de la frequence des relations thematiques des concepts constituant d'une combinaison conceptuelle. Unpublished manuscript.

Van Jaarsveld, H. J. \& Rattink, G. E. (1988). Frequency effects in the processing of lexicalized and novel nominal compounds. Fournal of Psycholinguistic Research I 7, 447-73. 